\title{
Raman Microscopic Analysis of a Multi-Pigmented Surface from the Theban Tomb (TT277), Luxor, Egypt
}

\author{
H.H. MAREY MahmoUD*
}

Department of Conservation, Faculty of Archaeology, Cairo University, 12613 Giza, Egypt

(Received October 22, 2012; in final form January 9, 2013)

In this study, the Raman microscopy technique was employed for identifying a multi-pigmented surface from the wall decorations of the Theban tomb (TT277), Luxor, Egypt. The Raman spectra were collected in the near infrared excitation line (785 nm Linefocus) of a diode laser source which enables mapping scan of specific areas in only few minutes. The microstructure and microanalysis of samples were performed by the aid of an environmental scanning electron microscopy coupled with an energy dispersive X-ray analysis system. The identified pigments were red ochre (haematite), yellow ochre (goethite) and carbon black (from a vegetable origin). Traces of anatase were found in the yellow coloured areas which can be a contaminant in natural iron oxide deposits. The ground layer was identified as anhydrite with minor amounts of calcium carbonates detected in some samples. The results showed the capability of the Raman microscopy for direct and fast identification of multi-pigmented surfaces in wall paintings and other decorative objects.

DOI: $10.12693 /$ APhysPolA.123.782

PACS: $82.80 . \mathrm{Gk}$

\section{Introduction}

The ancient city of Thebes is located on the western bank of the Nile River, about $650 \mathrm{~km}$ south of Cairo. The typical (elite) Theban tomb type is the rock-cut tomb that consists of two main parts, the underground burial chamber, most often undecorated and there is the decorated chapel accessible for the living [1]. At Thebes, the quality of stone is scarce, and therefore most of the tomb chapels were plastered and painted rather than decorated with reliefs. The Egyptians began serious colour manufacture from about $4000 \mathrm{BC}$. They introduced washing of pigments to increase their strength and purity. They also introduced new materials, the most famous of which was Egyptian blue, first produced around 3000 BC [2].

Materials analysis of artworks by modern analytical methods should be an integral part of pre-restoration research. In the case of wall paintings, analytical methods routinely used are light and electron microscopy with X-ray microanalysis (SEM-EDS). Microscopic methods are necessary for identification of the stratigraphy of painting layers. X-ray diffraction (XRD) is considered a very reliable tool for analysis of artist pigments. XRD helps in identifying very rare pigments, minerals composed of widespread elements, such as earth pigments [3], and pigments similar in elemental composition, such as copper-based pigments. At present, the only alternative analytical micro method to phase analysis is vibrational spectroscopy, either the Raman or IR spectroscopy. Vibrational spectroscopy is, however, sensitive only to certain phases or molecular structures, while practically each crystalline mineral can be revealed by XRD [4].

The Raman spectroscopy is a micro-analytical technique with with very advantageous features that allow its applications in the field of art and archaeology. Because of its sensitivity to chromophores, this technique

\footnotetext{
*e-mail: marai79@hotmail.com
}

is particularly suitable for the identification of pigments in complex matrixes and inorganic pigments in artworks [5-7]. The Raman spectroscopy is a form of vibrational spectroscopy, much like infrared (IR) spectroscopy. However, whereas the IR bands arise from a change in the dipole moment of a molecule, the Raman bands arise from a change in the polarizability. In many cases, transitions that are allowed in the Raman are forbidden in IR, so, these techniques are often complementary.

The Raman spectroscopy allows the identification of homogeneous materials on the basis of their molecular vibrational spectra, obtained by excitation with visible laser light. This spectroscopy is based on the Raman effect, which concerns to the molecular structure of the objects under analysis. When a monochromatic light impacts on a material, the light is scattered. Most of the scattered light has the same wavelength as the incident light (the Rayleigh scattering) and a small portion is shifted in wavelength due to molecular vibrations and rotations (the Raman scattering) [8]. With this spectroscopic technique, it is possible to analyze particles in the micron order and to identify species at molecular level with minimum or no preparation at all. In micro-Raman spectroscopy, the laser beam is focused by means of a microscope objective, employing a backscattering configuration; thus, the Raman scattered light is collected within the cone defined by the same objective [9]. Since the discovery of the Raman effect, instrumental improvements have continued to give new impulses to the Raman spectroscopic research such as are the introduction of lasers, Fourier transform (FT) Raman, charge-coupled device (CCD) detectors, confocal Raman spectroscopy and fiber-optics, that allowed conservation scientists to record molecular spectra of minute samples or directly from the art object [10].

\section{Experimental \\ 2.1. Samples}

Tiny pigmented layers from the detached plaster layers were collected from the wall decorations of the Theban 
tomb (TT277) from the 19th dynasty (c. 1293-1185 BC) (Fig. 1) which belongs to Amenemonet (the divine father of the temple of King Amenhotep III) at Qurnet Murai necropolis, western Luxor (about $670 \mathrm{~km}$ south of Cairo).

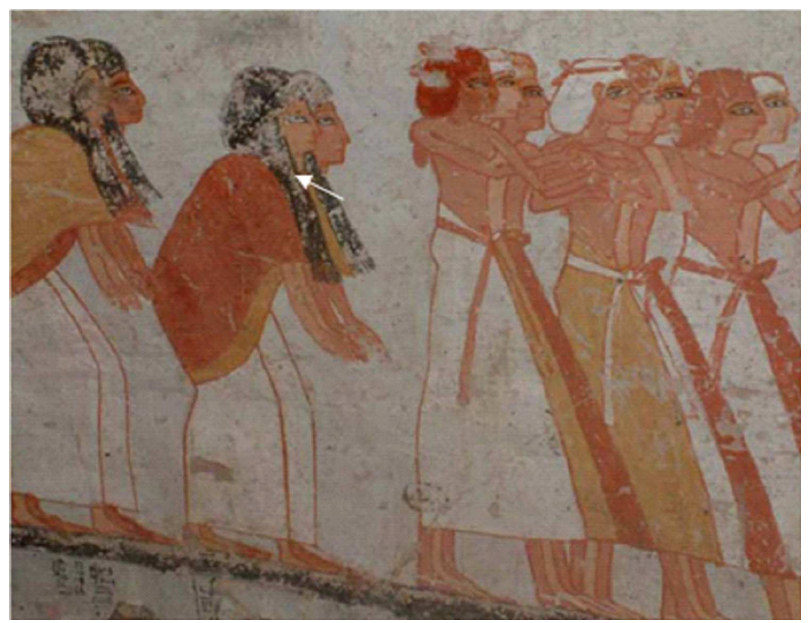

Fig. 1. View of the wall decorations of the tomb of Amenemonet (TT 277), Qurnet Murai necropolis, Luxor.

\subsection{Visual observations}

Preliminary observations on the samples were performed using an Olympus SZ-40 stereomicroscope (10 and $20 \times$ objectives) equipped with an Olympus DP10 digital camera. Optical observations of the cross-sections were carried out using an Olympus BX60 in reflection mode (with optical magnifications $50 \times$ to $500 \times$ ) equipped with a JVC KY-F1030 digital camera. The optical images were collected with reflected light and that helped to identify the structure of the paint layers and the colour of certain individual pigment grains.

\subsection{Raman microscopy}

The Raman spectra were recorded using a Renishaw InVia Raman spectrometer in the near infrared excitation line (Linefocus $785 \mathrm{~nm}$ ) of a diode laser source. The instrument is equipped with Peltier cooled charge coupled device (CCD $576 \times 400$ pixels). A Leica DMLM microscope with a $X Y Z$ motorized stage with 200 and 500 magnification objectives is equipped to the Raman spectrometer which can provide a sample irradiation diameter of up to $1 \mu \mathrm{m}$. A polarized unit system is mounted onto the microscope which offers a clear view of the area under investigation, necessary for positioning the beam on individual pigment particles. StreamLine imaging, available on inVia Raman microscopes, was applied to scan several areas on the painted surface in few minutes. Spectral acquisition was performed by (WiRE ${ }^{\mathrm{TM}}$, version 3.0) software.

StreamLine Plus uses optics within the InVia Raman microscope to illuminate a line on the sample. The InVia's motorized microscope stage moves the sample beneath the objective lens so that the line is rastered across the region of interest. Data are swept synchronously across the detector as the line moves across the sample, and are read out continuously. The ability to image areas larger than the field of view of the microscope not only enables large areas to be imaged, but it also allows areas to be imaged using high magnification objective lenses. According to Renishaw technical guide, StreamLine Plus is fast because sample movement, sample illumination, and data readout are performed simultaneously, rather than in series. StreamLine Plus's line focus sample illumination geometry gives lower power densities, enabling the maximum laser power to be employed. This ensures high data quality is maintained even at very fast acquisition speeds.

All Raman spectra were collected in static mode using the 1200 lines $/ \mathrm{mm}$ grating which allows achieving a spectral resolution of about $2 \mathrm{~cm}^{-1}$. The spectrometer was calibrated using the silicon spectral lines at $520.5 \mathrm{~cm}^{-1}$. Spectral measurements were carried out in the $100-2000 \mathrm{~cm}^{-1}$ range, exposure time was between 20 and $200 \mathrm{~s}$ while 4 up to 10 accumulations were co-added to produce the final spectrum in order to improve the signal-to-noise ratios. Data for Raman mapping over specific areas were collected over areas up to $100 \times 100 \mathrm{~mm}^{2}$ using a step size of $1 \mathrm{~mm}$, controlled by associated software. Micro-Raman spectral mappings of the samples were recorded using a motorized $X-Y-Z$ sample stage. The selected area on each sample was analyzed by successive point-by-point Raman acquisitions. At each point of the selected grid, the Raman spectrum was recorded using a $25 \mathrm{~s}$ integration time using the $500 \times$ magnification, with an effective power of 0.5 to $1 \mathrm{~mW}$ on the sample. In order to optimize the data collection, optimal $Z$-position of the sample, corresponding to the objective focal plane, was established before each spectrum acquisition.

\subsection{ESEM and X-ray microanalysis}

Samples were analyzed by environmental scanning electron microscope (ESEM) model Quanta FEG 250 (FEI, Netherlands). The FEI Quanta 250 is equipped with an energy-dispersive spectrometer (EDS) (an Oxford Aztec system) for elemental analysis on a microscopic scale. The accelerating voltage was $20 \mathrm{kV}$ and pressure of 2.0 Torr. Microanalysis of single pigment grains down to $1 \mu \mathrm{m}$, as well as of the matrix and the total average of the paint layer were performed. Also, some investigations on polished cross-sections were carried out.

\section{Results and discussion}

\subsection{Raman spectra}

The Raman spectra recorded of the red coloured area (Fig. 2) represent bands at 229, 297, 416, 503 and $613 \mathrm{~cm}^{-1}$ are in the spectra of haematite $\left(\alpha-\mathrm{Fe}_{2} \mathrm{O}_{3}\right)$, red ochre [11]. A light red tonality was produced by as a mixture of haematite, anhydrite and calcite. The dominant Raman band at $1019 \mathrm{~cm}^{-1}$ is likely due to the symmetric stretching ( $\nu_{1}$ vibration) of $\mathrm{SO}_{4}$ in anhydrite $\left(\mathrm{CaSO}_{4}\right)$ 
and the band detected at $1089 \mathrm{~cm}^{-1}$ is likely due to the presence of calcite $\left(\mathrm{CaCO}_{3}\right)$. A light red tonality was produced by a mixture of haematite, anhydrite and calcite. The Raman spectra recorded of the yellow coloured area (Fig. 3) show bands at 383, 297 and $557 \mathrm{~cm}^{-1}$ are in the spectra of goethite $(\alpha-\mathrm{FeOOH})$, yellow ochre [9]. Howsoever, the band detected at $148 \mathrm{~cm}^{-1}$ is characteristic of titanium dioxide phase anatase $\left(\mathrm{TiO}_{2}\right)$ which can be a contaminant in natural iron oxide deposits.

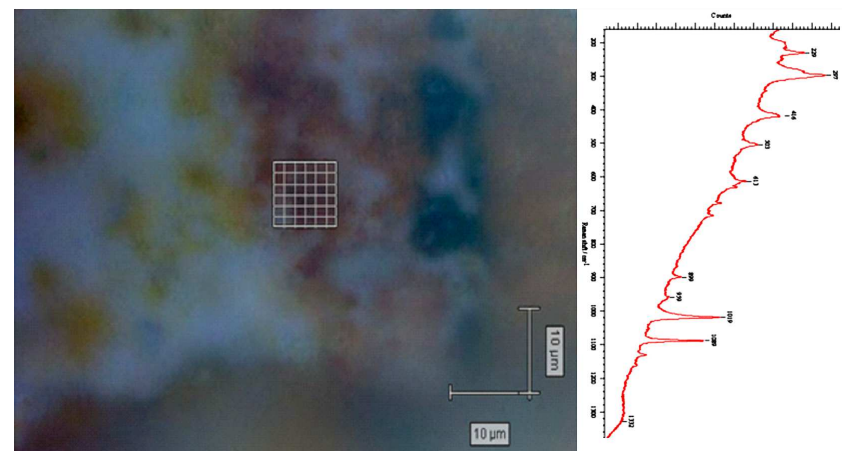

Fig. 2. Raman spectra collected on the red coloured area pigment ( $1 \mathrm{~mW}, 20$ accumulations and time of exposure of $20 \mathrm{~s}$ ).

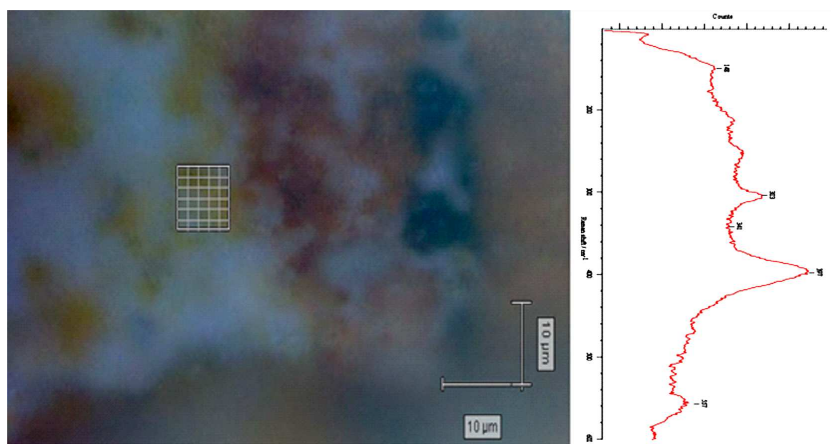

Fig. 3. Raman spectra collected on the yellow coloured area pigment $(0.5 \mathrm{~mW}, 20$ accumulations and time of exposure of $20 \mathrm{~s}$ ).

Pigments made from ochre are often discovered as long-lasting colorful remains in archaeological contexts. These striking minerals are found in the famous rock art paintings such as the prehistoric cave art at Lascaux, France, to modern paintings and frescoes. Red and yellow ochres were widely used without interruptions from the 5th Dynasty (c. 2494-2345 BC) till the Roman period in Egypt [12]. The definition of ochre is vague, as ochre can vary in mineralogical content from a pure iron oxide to a diluted mixture of iron oxide and other minerals. Ochre is typically composed of two common forms of iron oxide $\left(\mathrm{Fe}_{2} \mathrm{O}_{3}\right.$ and $\left.\mathrm{FeO}\right)$, mixed with clays, silicates, and other minerals and they range in color from deep purple to light yellow [13].

The Raman spectra recorded on the black coloured area (Fig. 4) show bands at 138, 1481 and $1584 \mathrm{~cm}^{-1}$

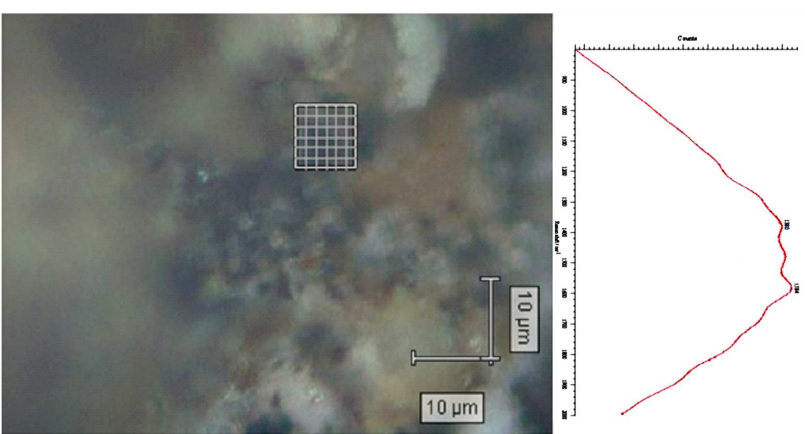

Fig. 4. Raman spectra collected on the black coloured area pigment $(0.5 \mathrm{~mW}, 20$ accumulations and time of exposure of $20 \mathrm{~s})$.

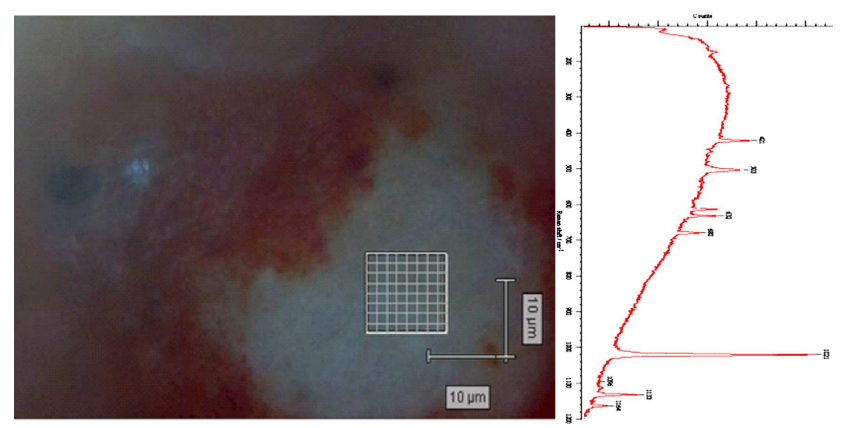

Fig. 5. Raman spectra collected on the underlying preparation layer $(1 \mathrm{~mW}, 20$ accumulations and time of exposure of $20 \mathrm{~s}$ ).

which are due to carbon black. No Raman bands were detected at $960 \mathrm{~cm}^{-1}$, the stretching of the phosphate ion $\left[\mathrm{PO}_{4}\right]^{3-}$, so the presence of ivory black and bone black may be excluded and the indication of a vegetable origin of the carbon is arisen [14]. Black pigments of vegetable origin have generally been made from various kinds of charred plant matter, mostly wood, but also leaves or seeds; the charcoal formed during the charring process is then washed, to remove soluble matter, and finally ground to powder [15].

The Raman spectra obtained on the preparation layer (Fig. 5) show a strong band at $1021 \mathrm{~cm}^{-1}$ which is due to anhydrite. The $\nu_{2}$ and $\nu_{3}$ modes of sulfate tetrahedra split in two bands [16]: one at $421 \mathrm{~cm}^{-1}$ and $503 \mathrm{~cm}^{-1}$ and the other one at $1133 \mathrm{~cm}^{-1}$ and $1164 \mathrm{~cm}^{-1}$, while the bands at 632 and $683 \mathrm{~cm}^{-1}$ are for $\nu_{4}$ anti-symmetric bending vibration modes.

\subsection{Microstructure and microanalysis (ESEM-EDX)}

A representative ESEM image obtained on a polished cross-section of the red paint layer is given in Fig. 6 . The ESEM image shows granular fine and coarse aggregates of the ochre pigment material. The EDX microanalysis of the sample shows high concentration of $\mathrm{Fe}$, which indicates the existence of iron oxide as the possible material producing the red colour. Minor elements of $\mathrm{Si}, \mathrm{Ca}$ and $\mathrm{S}$ were found together with traces of $\mathrm{Al}, \mathrm{Na}, \mathrm{K}, \mathrm{Ti}$ and $\mathrm{Cl}$. The contribution of $\mathrm{Si}$ and $\mathrm{Al}$ is likely due to the 
existence of an aluminosilicate material (e.g. clay minerals which could be primary accessory minerals in ochre pigments) [17]. The S and Ca peaks are attributed to calcium sulphate phases from the underlying ground layer. Investigation on the yellow coloured areas showed almost similar composition of the red ones. While the EDX microanalysis of the black grains shows sharp $\mathrm{C}$ peak, the absence of phosphorus in the sample is another indication that the black carbon was obtained from a burnt vegetal matter.

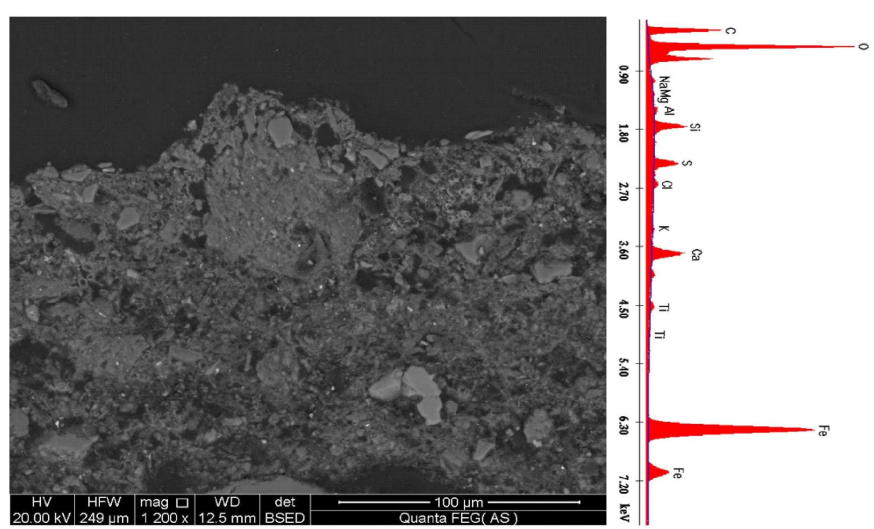

Fig. 6. (left) ESEM image $(1200 \times$, bar $100 \mu \mathrm{m})$ and (right) EDX spectrum obtained on polished cross-section of the red paint layer.

\section{Conclusions}

By applying the Raman microscopy and ESEM-EDX techniques, the chemical and molecular structure of a multi-pigmented surface from the Theban tomb (TT277) at Qurnet Murai necropolis, western Luxor were successfully identified. The results showed that the used pigments are red ochre (haematite, $\alpha-\mathrm{Fe}_{2} \mathrm{O}_{3}$ ), yellow ochre (goethite, $\alpha$-FeOOH) and carbon black (from a vegetable origin). Traces of titanium dioxide phase anatase $\left(\mathrm{TiO}_{2}\right)$ were detected in the yellow pigment samples which can be contaminant in natural iron oxide deposits. The preparation layer was made of anhydrite with different proportions of calcium carbonate (calcite). This contribution demonstrates the capability of the Raman microscope to fast and non-destructive identification of several coloured areas on the painted surfaces in only few minutes.

\section{Acknowledgments}

The author is grateful to the archaeologists and conservators at the Supreme Council of Antiquities (SCA), the local office of Luxor for their assistance through collecting samples.

\section{References}

[1] J. Kamil, LUXOR: A Guide to Ancient Thebes, 2nd Ed., Longman, London 1976.

[2] J.R. Barnett, S. Miller, E. Pearce, Optic. Laser. Technol. 38, 445 (2006).

[3] D. Hradil, T. Grygar, J. Hradilova, Appl. Clay Sci. 22, 223 (2003).

[4] V. Simova, P. Bezdicka, J. Hradilova, D. Hradil, T. Grygar, Powder Diffr. 20, 3 (2005).

[5] H.G.M. Edwards, D.W. Farwell, E.M. Newton, F. Rull Perez, F.S.J. Villar, J. Raman Spectrosc. 31, 407 (2000).

[6] K.Z. Castro, M. Pérez-Alonso, Z.M.D. RodriguezLaso, L.A. Fernández, M.Z.J. Madariaga, Anal. Bioanal. Chem. 382, 248 (2005).

[7] D. Marano, I.M. Catalano, A. Monno, Spectrochim. Acta A 64, (2006).

[8] Analytical Raman Spectroscopy, Eds. J.G. Grasselli, B.J. Bulkin, Chichester, Wiley 1991.

[9] A. Perardi, L. Appolonia, P. Mirti, Anal. Chem. 480, 269 (2003).

[10] P. Vandenabeele, J. Raman Spectrosc. 35, 607 (2004).

[11] R.A. Goodall, J. Hall, H.G.M. Edwards, R.J. Sharer, R. Viel, P.M.J. Fredericks, J. Archaeol Sci. 34, 4 (2007).

[12] A. El Goresy, in: Proc. First Thera Int. Symp., Ed. P.M. Nomikos, Thera Foundation, Piraeus 1997, p. 49.

[13] R.S. Popelka-Filcoff, J.D. Robertson, M.D. Glascock, Ch. Descantes, J. Radioanal. Nucl. Chem. 272, 1 (2007).

[14] F. Ospitali, D.C. Smith, M. Lorblanchet, J. Raman Spectrosc. 37, 1063 (2006).

[15] Z. Goffer, Archaeological chemistry, 2nd ed., John Wiley, Hoboken (NJ) 2007.

[16] Romanian Database of Raman Spectroscopy, website: http://rdrs.uaic.ro/ .

[17] H.H. Marey Mahmoud, Mediter. Archaeol. Archaeom. 11, 1 (2011). 